\title{
Perception of Consumer Rights among the College Students: A Case of Tikapur Municipality ${ }^{1}$
}

\author{
Dhabindra Rawal
}

\begin{abstract}
This study aims at examining consumes' perception towards marketing practices and consumer rights in Tikapur Municipality, Kailali based on an empirical study of college students in connection to John Kennedy's bill of four consumer rights, namely, the right to safety, the right to be informed, the right to choose, and the right to be heard. This study depends on a convenience sample of 60 students selected from Management, Education and Humanities faculties studying in graduate level at Tikapur Multiple Campus and Birendra Vidhya Mandir Campus at Tikapur, with a structured questionnaire to measure consumer attitudes regarding the four basic consumer rights, utilizing a fivepoint Likert Scale for measurement. The overall findings communicate that the current consumers' attitudes towards marketing practices related to protection of consumer rights is low favorable, indicating that more work will be needed for improvement. This study explores the status of perceived consumer rights for the first time in study area. It suggests marketers and public policy makers to pay more attention to the current status of consumer rights, and formulate more useful legislations with implications for better business strategies.
\end{abstract}

Keywords: consumer rights, consumer perception, consumer awareness, consumerism, corporate social responsibility, business ethics

\section{Introduction}

A consumer is a buyer who buys goods and services for personal and family consumption and not for the resale or commercial purposes. Consumer Protection Act (1998) defined that consumer is an individual or institution consuming or using any consumer goods or services. Consumer is the key element of the market and they play a vital role in the economic system of a nation. Consumer perception theory tries to analyze and explain the behavior of consumers. Marketing activities are influenced by consumer perception. Consumer awareness is an act of making the buyer or consumer sure about the information of products, services, and consumers rights. John Fitzgerald Kennedy, the 35th President of the United States initiated consumer protection concept for the first time on 15th March 1962. He has declared this concept in the US Parliament stressing on the protection of consumer's interest. Kennedy spoke about the four basic rights of consumer, namely, rights to safety, rights to be informed, rights to be heard, and rights to choose (Sekhar, 2018). In Nepal, consumers have the right to be protected, rights to be informed, rights to choose, rights to be heard and rights to consumer education (Consumer Protection Act, 1998). The Act has reserved the rights and interests of all Nepalese consumers.

The main objective of this study is to assess perceptions towards marketing practices related to consumer rights based on attitudinal survey of college (University) students in Tikapur Municipality, Kailali, Nepal. This study basically employs John F. Kennedy's bill of four basic consumer rights, namely, rights to safety, rights to be informed, rights to choose, and rights to be heard.

\section{Statement of problem}

Every consumer buys a variety of goods and services in his day-to-day life in the market for the fulfillment of needs. But sometimes consumers do not feel satisfied with the purchased products and services. This may be on account of poor quality or harmful product, poor services, over pricing by the shopkeeper, lower quantity of contents, unclear product labeling, deceptive packaging, false promise, and misleading advertisement, to name a few. The requirements of adopting measures to protect the concerns of consumers arise chiefly due to their helpless position. These problems are mostly situated in the markets of underdeveloped and developing countries. The fact cannot be rejected that the consumers have the basic rights to be protected from the loss or injury caused on account of defective goods and deficiency of services. Alsmadi and Khizindar (2015) explained that many consumers are violated in the market, as their basic rights are seriously threatened by unethical marketing behavior; often, competition for custom, coupled with unclear code of marketing conduct, in some cases, create opportunities

\footnotetext{
${ }^{1}$ Cite this article as: Rawal, D. (2019). Contemporary Research: An Interdisciplinary Academic Journal, vol. 3 (1): Dhabindra Rawal, Associate Professor, Tikapur Multiple Campus, Far Western University, Nepal Email: rawald786@gmail.com

Peer reviewed under the authority of CRAIAJ, academic journal of Ghodaghodi Multiple Campus, Kailali, Nepal. (C) 2019 Contemporary Research: An Interdisciplinary Academic Journal
} 
that remove barriers to act unethically, particularly when commitment to corporate social responsibility and business ethics are weak. In such a business environment, this could lead to serious abuse of consumer rights and a drift into a much dishonest marketing behavior.

Therefore, every individual needs to be aware of their rights as a consumer. Consumer should learn how to protect oneself and how to become a rational buyer while shopping online or offline. Students are important targeted market segment who require attention from a marketing perspective. They are also facing a number of marketing problems during the shopping of the product. There are many malpractices in bills, records, warrantee cards, date of manufacturing, weight measurements, maximum retail price etc. Therefore, it is needed to identify the perceptions on consumer rights of students at graduate level. So, following research questions is raised for present study:

- What are the consumers' (students) perceptions of their rights about the marketers' practices?

\section{Research hypothesis}

This study is guided by four hypotheses which are based on research article "Consumers' Perceptions of Consumer Rights in Jordan” by Alsmadi and Khizindar (2015). Following hypotheses are formulated to be verified empirically in this study:

H1: Consumers are generally favorable about marketers' practices related to their right to safety.

H2: Consumers are generally favorable about marketers' practices related to their right to be informed.

H3: Consumers are generally favorable about marketers' practices related to their right to choose.

H4: Consumers are generally favorable about marketers' practices related to their right to be heard.

\section{Review of literature}

This study tries to analyze the findings of previous studies relevant to consumer perceptions, awareness and consumer rights. A study addressed the level of awareness of Jordanian consumers to their rights to safety with regard to food products and concluded that consumers were highly aware of product safety issues and interested in paying extra price for higher safety standards (Qtaishat et al., 2002). In Saudi Arabia, a study of consumer rights showed that the consumer voice did not seem to be well represented in the process of economic planning and policy development and that consumer issues were beginning to be taken seriously by public policy makers (Morris and Al Dabbagh, 2004). On food safety, a Dutch study recommended to install an independent advisory committee to help the government to set the rights level of safety protection on food products (Swarte and Donker, 2005). A study in the Jordanian context showed that consumers were not generally happy with the informational aspect of marketing communications (Alsmadi and Al-Zobi, 2005). A study in drugs field revealed that the level of believable information on drug side effects was only 31 per cent, with only 28 per cent level of credibility on drug benefits (Beltramini, 2006). A study in Palestine examined consumer protection in electronic contracting and concluded that consumers would need more protection in terms of their "Right to be Informed" in electronic buying (Mahmoud, 2009). A study of legislation pertaining to consumer protection in India revealed that consumer rights were deeply rooted in the Indian legislative system and that consumer disputes were handled in a novel way in Indian consumer courts (Prasad, 2009).

A study of consumer rights regarding the Right to Information, conducted for the European Commission, concluded that the non-disclosure of consumer information was likely to cause problems including reduction of the level of consumer protection (Danguole, 2011). In the Jordanian context, a study explored the extent to which the Electronic Transactions Law in Jordan addressed various consumer protection issues in an online environment and recommended relevant perspectives on how to deal with such issues (Dahiyat, 2011). Kulkarni \& Mehta (2013) found that most of the management students are aware of consumer rights but they never lodge the complaints against traffickers. Khan (2013) focused that the consumer rights awareness is much needed today as they pay for the products from their hard earned money and they should get it worth. Alsmadi and Khizindar (2015) found that consumers' attitudes toward marketing practices related to protection of consumer rights is not highly favorable, indicating that more work will be needed for improvement, with more attention to consumers' rights to be heard. Permila (2016) studied the awareness on consumer rights of student- teachers and found that Students and teachers are having high awareness about consumer rights but there is significant difference on awareness level of consumer rights of student- teachers with regard to gender, subject, locality, qualification, and age. Indirani et al. (2016) indicated the result of study that awareness of consumer rights among the college students is average level. It means that students' awareness of consumer rights is found to be satisfactory. Chaudhary (2017) conducted the research study on consumer awareness among 
college student in Assam, Tejpur and he concluded that right from birth each and every one of us becomes a consumer but people are less aware about the rights and responsibilities they have as a consumer. There is a need of education for awareness of consumer rights, responsibilities and the complaint handling among people of all age groups. People are less aware of the movement of consumerism and handling customer complaints.

The clear vision came out about the consumer protection since the 1960s. After that, scholars have conducted research related to consumer protection areas with much focus on the western perspective. The most salient aspect was the debate about the imbalance of power between marketers and consumers. Implicitly, basic consumer rights were not always protected, as clearly revealed in the literature, particularly in many developing countries. In developing countries, poor condition has been found and gradual improvements in the protecting basic consumer rights have been realized. In south Asian context, very few research studies have been found in consumer awareness area especially in check and read the labeling information, assurance marks, consumer rights and various problems faced by them while shopping the products and among them much more studies are conducted in the context of India. There is no study found about the consumer awareness and perception of consumer rights related content in the context of Nepal. So, this study is expected to fulfill research gap of location and time.

\section{Research design}

This study analyses perception of consumers (students) towards consumer rights in Tikapur Municipality, Nepal by employing descriptive research design. Nature of perception is qualitative, but it is quantified for measurement. So this empirical study is qualitative and quantitative (mixed) in nature and involved the use of structured questionnaires which are designed to obtain objectives of the study.

\section{Population and sample}

This study is based on empirical investigation of a student population of two campuses in Tikapur Municipality, Kailali, Nepal. A convenience sampling procedure was applied in this research study. The sample size of population was 60 students selected from graduate level of colleges. All questions were usable or response rate was 100 percent. In this study, 50 percent of the respondents were female. In term of educational faculties, 50 percent respondents belonged to Management faculty and remaining 50 percent were from Education and Humanities faculties. Majority of the respondents (66.7\%) were from Tikapur Multiple Campus and 33.3 percent from Birendra Viddhya Mandir Campus.

\section{Sources of data}

The data have been collected from primary sources. A structured questionnaire was prepared to collect the data from different respondents. Convenience sampling technique was followed to gather the opinions of respondents. Although the study was based on primary source of data some secondary sources were also used wherever necessary. Secondary data refer to materials or information collected previously by the researcher or through existing body of the knowledge: books, newspapers, journals, magazines, online and other available sources.

\section{Research instrument}

A structured questionnaire was used to measure consumer attitudes towards marketers' practices related to consumer rights, focusing on the four basic consumer rights, each in a separate section as a main dimension. This study was guided by attitude statements check list developed by Alsmadi and Khizindar (2015) to measure each of the four consumer rights in each dimension as right to safety (D1), right to be informed (D2), right to choose (D3) and right to be heard (D4). All perception statements of consumer rights ware measured in five-point Likert Scale of agreement running from strongly disagree to strongly agree with a neutral category for midpoint scale $(1=$ strongly disagree, $2=$ disagree, $3=$ neutral, $4=$ agree and $5=$ strongly agree). As the measuring statements were all positively phrased, the measurement logic maintains that the higher the attitude mean score the more favorable the attitude and vice versa.

\section{Reliability test analysis}

To find out the reliability of the collected final data, the information has been entered in SPSS software 20 version and Cronbach alpha test has been conducted for the entire Likert Scale questions dimension wise. The reliability of the whole measuring instrument was tested by Cronbach's alpha for internal consistency which showed satisfactory Cronbach's alpha value ranged from 0.72 to 0.84 and 0.88 as a whole instruments as can be seen in the table 1 . 
Rawal, D. (2019), CRAIAJ, vol. 3 (1): 25-32

Table 1 Cronbach's alpha for internal consistency coefficients for consumer rights dimensions

\begin{tabular}{ll}
\hline Consumer rights dimension & Cronbach's alpha value \\
\hline D1: Right to Safety & 0.79 \\
D2: Right to be Informed & 0.78 \\
D3: Right to Choose & 0.84 \\
D4: Right to be Heard & 0.72 \\
Instrument as a whole & 0.88 \\
Note: $N=60$ &
\end{tabular}

Statistical Procedures

In this study, collected information and data were coded and entered in the SPSS software. Data analysis was performed by using the statistical package SPSS software 20 version. Statistical tools were used for data analysis and hypotheses testing, including descriptive statistics and ANOVA (One-sample $t$-test). The Likert measuring scale is divided into three scoring areas. As the length category for the scale is 1.33 , (resulting from $1-5 / 3=1.33$ ), the three categories are: low favorable attitude $[1.00 \leq$ mean score $(\mathrm{MS}) \leq 2.33]$, medium favorable attitude $(2.33 \leq \mathrm{MS} \leq 3.66)$ and high favorable attitude $(3.66 \leq$ MS $\leq 5)$. One-sample $t$-test was further used to substantiate the difference between the relevant mean score and the criterion value (3) based on a statistical significance level of 5 percent $(\alpha \leq 0.05)$. P-value was determined to accept or reject the hypotheses, as assuming favorable attitude about marketers' practices related to the consumer rights.

\section{Data analysis and discussion of results}

\section{First Dimension (D1): Right to safety}

The table 2 expresses the descriptive statistics for the attitude statements of first dimension (D1) right to safety and the results of one-sample $t$-test. The analysis shows that only one statement is related to medium favorable attitude and all others attitude statements of consumers were low favorableness about marketers' practices related to their right to product safety, with an overall mean score $(2.23)$ for the whole dimension being in the low favorable attitude category $(1 \leq \mathrm{MS} \leq 2.33)$ and relatively low standard deviation value (0.69). All the six attitude statements, which were used for measuring this dimension, were in the generally low scoring area. The lowest mean score was 1.90 relating to the statement as I feel that all marketers are concerned about product safety, while the highest one was 3.17 relating to the statement as I feel 'peace of mind' for my safety when I use the products I buy from the market. Clearly, this indicates overall low satisfaction with respondents' right to safety. Attitude statements showed that most consumers were not sure government and all marketers were really concerned about product safety. They also could not found comfortable and safety standards product for health, further more reflecting that they may have encountered some product problems in the past. As a whole, shows that the overall attitudes were low favorable, with an overall mean score of 2.23. In this study, the results were further substantiated by one-sample $t$-test for the dimension as a whole, which revealed a relatively $t$-value $(-8.53)$ with statistical significance $(\mathrm{P}$ value $=0.000)$. Clearly, the results of one-sample $t$-test supported $H 1$ or accepted the hypothesis one, which states that consumers are generally favorable about marketers' practices related to their right to safety.

Table 2 Descriptive statistics for attitude statements of right to safety, listed in a descending order according to mean score value

D1: Right to safety items $\quad$ Rank MS* Attitude favorableness**

I feel "peace of mind" for my safety when I use the $\quad \begin{array}{llll}1 & 3.17 & \text { medium favorable attitude }\end{array}$ products I buy from the market

I feel comfortable about my health when I use the $\quad \begin{array}{lll}2 & 2.27 & \text { low favorable attitude }\end{array}$ products I buy from the market.

I feel that the government is concerned about product

$3 \quad 2.12 \quad$ low favorable attitude

safety 


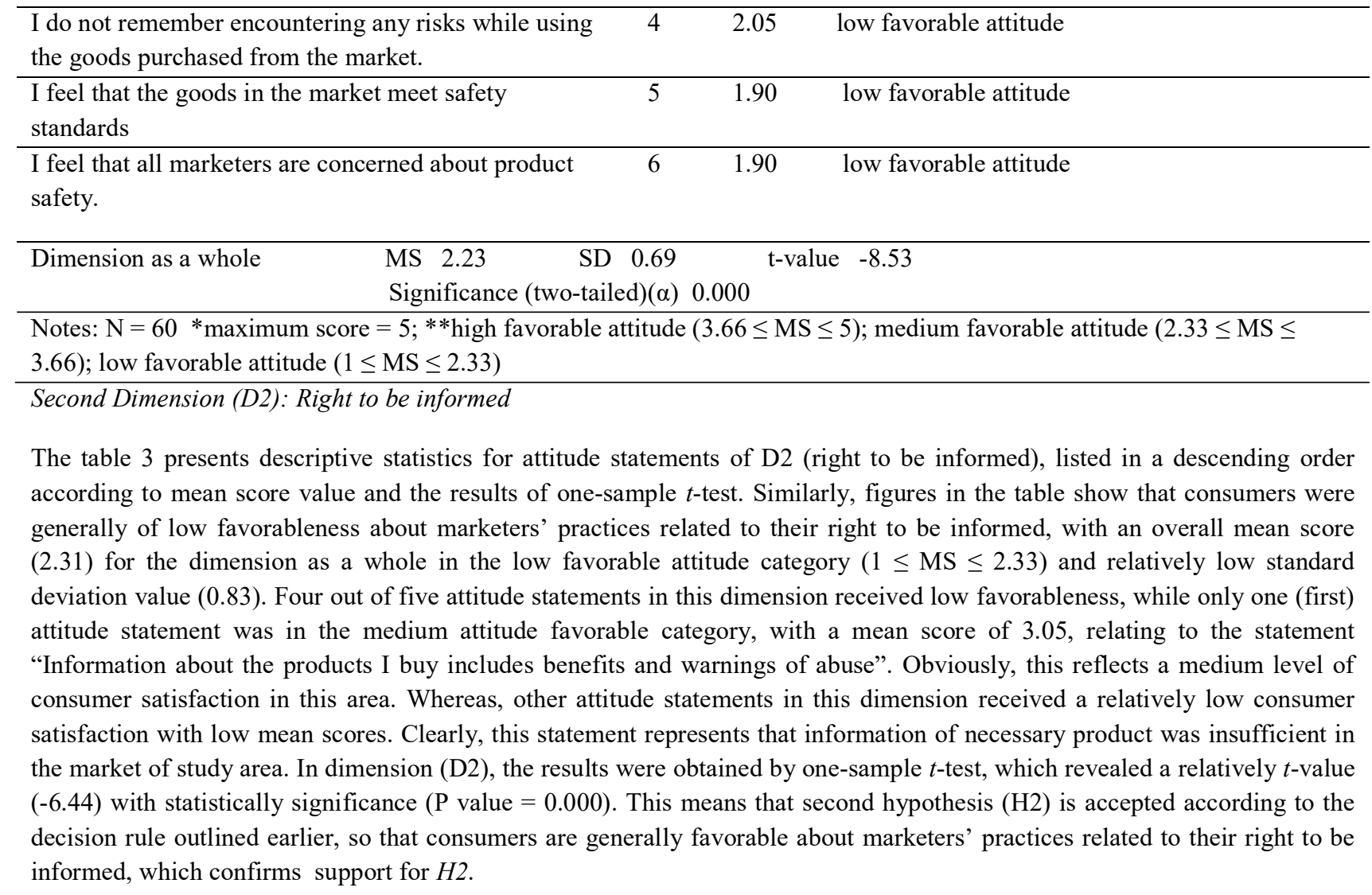

Table 3 Descriptive statistics for attitude statements of right to be informed, listed in a descending order according to mean score value.

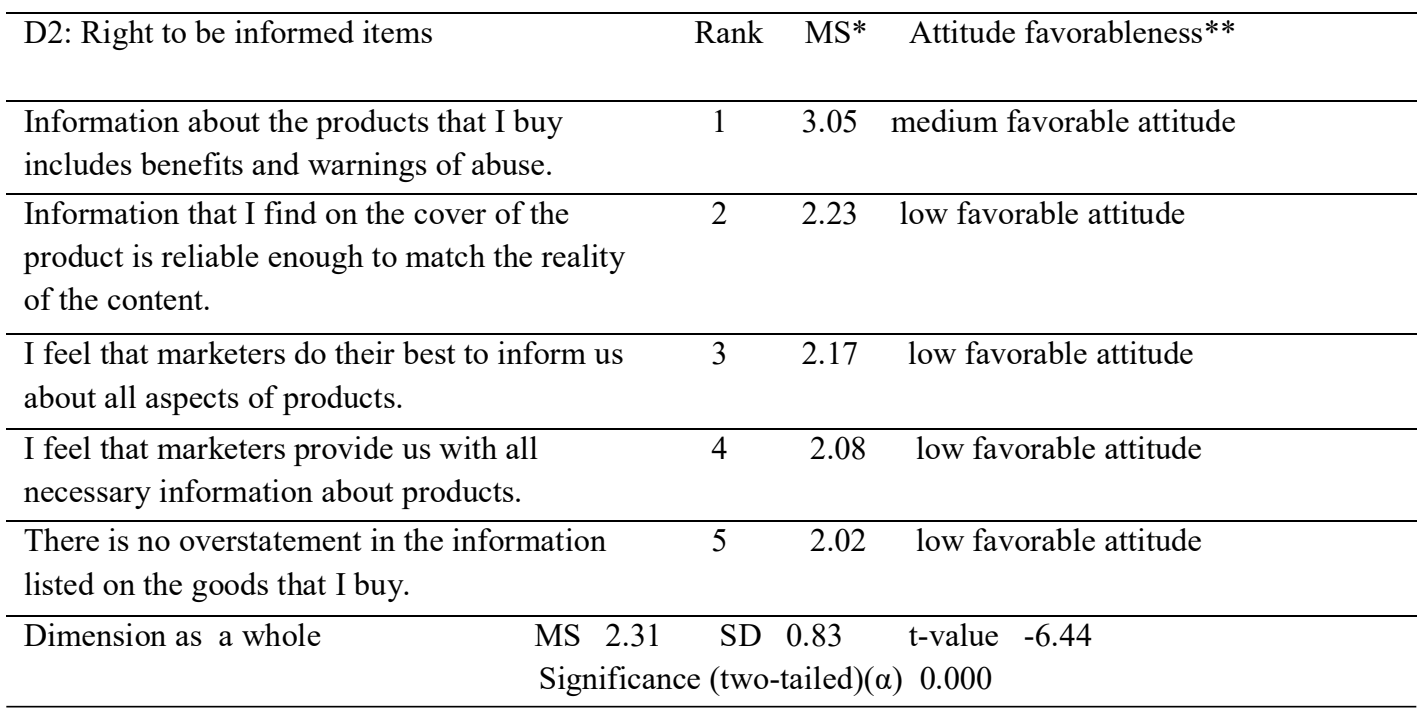

Notes: $\mathrm{N}=60 *$ maximum score $=5 ; * *$ high favorable attitude $(3.66 \leq \mathrm{MS} \leq 5)$; medium favorable attitude $(2.33 \leq \mathrm{MS} \leq 3.66)$; low favorable attitude $(1 \leq \mathrm{MS} \leq 2.33)$

\section{Third Dimension (D3): Right to Choose}

Table 4 shows the results of descriptive statistics for the attitude statements in the third dimension (D3) of the study right to choose. The analysis of the data shows that consumers were low favorable about their marketers' practices related to their right to choose, with an overall mean score (2.17) for the dimension as a whole being in the low favorable attitude category $(1 \leq \mathrm{MS}$ $\leq 2.33$ ) and relatively low standard deviation $(0.85)$, revealing little dispersion around the mean. More specifically, the all five attitude statements in this dimension received low favorableness, of which the mean score value ware maximum 2.33 to minimum 1.98, In general, this dimension looks also lower satisfaction. The results were further enhanced by one-sample $t$ - 
test for the dimension, as a whole, which indicated a $t$-value $(-7.52)$ with statistical significance $(\mathrm{P}$ value $=0.000)$. This means that third hypothesis is also accepted in this study as consumers are generally favorable about marketers' practices related to their right to choose, which further supported to $H 3$.

Table 4 Descriptive statistics for attitude statements of right to choose, listed in a descending order according to mean score value

\begin{tabular}{|c|c|c|}
\hline D3: Right to choose items & Rank MS* & Attitude favorableness $* *$ \\
\hline $\begin{array}{l}\text { There are always several options available } \\
\text { for the consumer to choose products } \\
\text { verities in the market. }\end{array}$ & 2.33 & low favorable attitude \\
\hline $\begin{array}{l}\text { Products diversity in the market is enough } \\
\text { to meet all tastes. }\end{array}$ & 2.33 & low favorable attitude \\
\hline $\begin{array}{l}\text { Different versions of products are } \\
\text { available to cater for different consumer } \\
\text { budgets. }\end{array}$ & 2.22 & low favorable attitude \\
\hline $\begin{array}{l}\text { I never had to choose unsuitable products } \\
\text { due to lack of alternatives. }\end{array}$ & 2.00 & low favorable attitude \\
\hline $\begin{array}{l}\text { Wide varieties of products are usually } \\
\text { available in different market areas to meet } \\
\text { the needs of consumers in different places. }\end{array}$ & 1.98 & low favorable attitude \\
\hline \multirow[t]{2}{*}{ Dimension as a whole } & SD 0.85 & t-value -7.52 \\
\hline & ce $($ two-tailed $)(\alpha)$ & 0.000 \\
\hline \multicolumn{3}{|c|}{$\begin{array}{l}\text { Notes: } \mathrm{N}=60 * \text { maximum score }=5 ; * * \text { high favorable attitude }(3.66 \leq \mathrm{MS} \leq 5) ; \text { medium favorable } \\
\text { attitude }(2.33 \leq \mathrm{MS} \leq 3.66) ; \text { low favorable attitude }(1 \leq \mathrm{MS} \leq 2.33)\end{array}$} \\
\hline
\end{tabular}

Table 5 communicates the descriptive statistics for the attitude statements in the fourth dimension (D4) and the results of onesample $t$-test. The analysis shows that consumers were generally of low favorable about marketers' practices related to their right to be heard, with an overall mean score (1.9) for the whole dimension being in the low favorable attitude category (1 $\leq$ MS $\leq 2.33$ ) and relatively low standard deviation value $(0.62)$. The table reveals that all the five attitude statements, which were used for measuring this dimension, were in the low scoring area. The attitude statement, with the highest mean score (2.15), was relating to the statement as Company management takes consumer feedback seriously and usually acts accordingly. While the lowest mean score attitude in this dimension was (1.58) relating to the statement i.e. businesses usually announce free contact numbers for consumers to encourage them to express their opinions. Clearly, the findings in this dimension suggest that most consumers were not sure to taking consumer feedback seriously and acting accordingly and if making complaints were always easy. The overall picture in this table indicates that the dimension's mean score was low, with actually low attitude favorableness. It means reflecting relatively poor perception of consumer rights with regards to the right to be heard. Further analysis, using one-sample $t$-test, reveals a $t$-value $(-13.65)$ with statistical significance $(\mathrm{P}$ value $=0.000)$. This means that the overall mean score for this dimension, as a whole, was significantly different from the criterion value. Thus fourth hypothesis (H4) is also accepted, which states that consumers are generally favorable about marketers' practices related to their right to be heard. Therefore, it supports $H 4$.

Table 5 Descriptive statistics for attitude statements of right to be heard, listed in a descending order according to mean score value

\begin{tabular}{llll}
\hline D4: Right to be heard items & Rank & MS* & Attitude favorableness** \\
\hline $\begin{array}{l}\text { Company management takes } \\
\text { consumer feedback seriously and }\end{array}$ & 1 & 2.15 & low favorable attitude \\
\begin{tabular}{l} 
usually acts accordingly. \\
\hline $\begin{array}{l}\text { I do not feel difficult to complaint } \\
\text { about any aspect of business. }\end{array}$
\end{tabular} & 2 & 2.03 & low favorable attitude \\
\hline
\end{tabular}




$\begin{aligned} & \text { Marketers look appreciative when } \\ & \text { they receive any feedback from }\end{aligned}$
customer, irrespective of its nature.

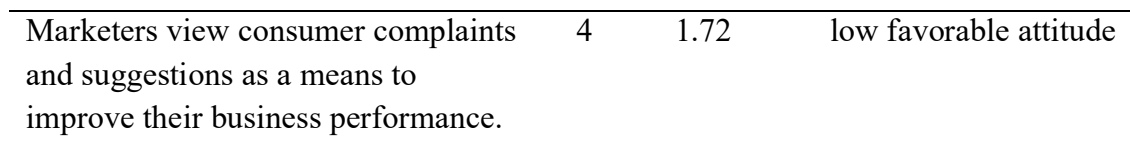

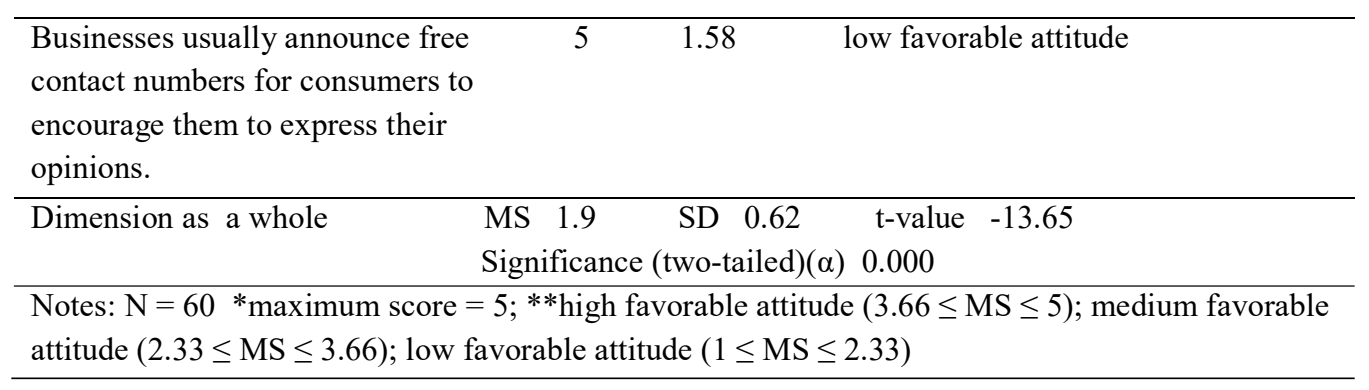

\section{Conclusion and implications}

The analysis indicates a significance of hypotheses as consumers are generally favorable about marketers' practices related to their rights. The overall findings of the study suggest that students attitudes pertaining to their perception of consumer rights were low favorable in Tikapur Municipality, with the lowest favorable attitude, particularly noted for the rights to be heard. College students did not believe in positive statement of consumer rights and role of the government in the Nepalese market. The current status of consumer protection is poor indicating that more effort is needed for improving quality of consumer protection, focusing on consumer's right to safety, right to be informed, right to be choose and specially right to be heard, as consumers were significantly concerned about it. Though Consumer Protection Act of Nepal (1998) has clearly defined and addressed about consumer rights, consumer protection council, supervision and control, provision of penalties and compensation etc., implementation part is very weak. Government has less concentration on consumerism, consumer rights, corporate social responsibility and other marketing unhealthy activities.

This study indicates that consumer protection position is weak with low favorable attitudes about marketers' practices related to consumer rights. Therefore, quality of consumerism should be improved in developing countries like Nepal. There is dire need to look at the experience of developed countries regarding the quality of consumerism which would provide a model of a desired marketing behavior. In Nepali context, standard of corporate social responsibility and businesses ethics should be improved. Today, standards of consumer protection must evolve and stand firmly to address various new challenges and opportunities.

This study has been conducted in limited area in only one Municipality of Nepal emphasizing only on students' perception with few samples. And very limited statistical tools such as percentage, mean score, standard deviation and one sample t-test are applied for data analysis. It may not be fully represent the perceptions of consumer rights for whole population. However, this study is meaningful and provides the direction to further studies in context of consumer awareness and rights. Additionally, the outcomes of the study is expected to help Nepalese policy makers and consumer forums to understand the perception of consumer rights among the college students, implications for future business strategies and public policies will be highlighted for possible future actions. Legislators may also draw on such findings in drafting more useful legislations pertaining to consumer protection. Furthermore, the result of this study is expected to useful for other contexts of similar socio-economic and regulatory status of the developing countries.

Future research can be conducted in large sample in different areas in the different regulatory, political, socio-cultural and economic environments. Furthermore, the study also can be conducted on consumer awareness, perception of consumer rights, its impacts on buying behavior in different demographic variables, i.e., gender, age group, occupations, urban and rural consumers and psychographic variables. 
Rawal, D. (2019), CRAIAJ, vol. 3 (1): 25-32

\section{References}

Alsmadi, S. and Al-Zobi, M. (2005). Consumer attitudes towards marketing deception: An empirical study of consumer behavior in the city of Irbid. Journal of Abhath Al-Yarmouk, 21 (2), 293-320.

Alsmadi, S. and Tariq, K. (2015). Consumers' perceptions of consumer rights in Jordan. International Journal of Commerce and Management, 25(4), 512 - 530.

Beltramini, R.F. (2006). Consumer believability of information in direct-to-consumer (DTC) advertising of prescription drugs. Journal of Business Ethics, 63 (4), 333-343.

Chaudhury, K. (2017). Consumer awareness among the college students. International Journal of Research - Granthaalayah, 5 (6), $223-230$.

Consumer Protection Act, 2054 (1998). Protection and promotion of consumer rights. Retrieved from www.lawcommission.gov.np.

Dahiyat, E. (2011). Consumer protection in electronic commerce: some remarks on the Jordanian electronic transactions law. Journal of Consumer Policy, 34 (4), 423-436.

Danguole, B. (2011). Language: Lithuanian. Jurisprudence, 18 (4), 1593-1608.

Indirani, N. and Kumar, A. C.(2016). Awareness on consumer rights among undergraduate students in Tiruchirappalli City. International Journal of Educational Investigations, 3 (3), 63-74.

Khan, M. A. (2013). Consumer rights awareness in urban and rural areas of Muzaffarnagar and Saharanpur districts: An empirical study. Cited from http://shodhganga.inflibnet.ac.in/bitstream

Kulkarni, M. S. and Mehta, M. B.(2013). Buying practices and consumer rights awareness management students. International Journal of Management, 1, 78-85.

Mahmoud, A. (2009). Consumer protection in electronic contracting: Comparative study. Unpublished Master's degree, Najah National University, Palestine.

Morris, D. and Al Dabbagh, M. (2004). The development of consumer protection in Saudi Arabia. International Journal of Consumer Studies, 28 (1), 2-13.

Prasad, A.R. (2009). Arbitration and consumer protection: the Indian perspective. ICFAI University Journal of Alternative Dispute Resolution, 8 (1), 49-56.

Parmila, S. (2016). Awareness on Consumer Rights of Student- Teachers. International Research Journal of India, 2 (3), 1- 4.

Qtaishat, T., Al-Rimawi, A. and Al-Karablieh, E. (2002), Consumer awareness of food safety and willingness to pay for integrated pest management products in Jordan, Dirasat-Agricultural Sciences, 29 (3), 315-322.

Sekhar, S. (2018). The history of consumer protection. Retrieved from www.lawtimesjournal.

Swarte, C.D. and Donker, R.A. (2005). Towards an FSO/ALOP based food safety policy. Food Control Issue, 16 (9), 825-830. 